\title{
sciendo
}

DOI: $10.2478 /$ rjp-2019-0018

Rom J Psychoanal 2019, 12(2):93-106

Rom J Psychoanal

\section{THE PLACE AND ROLE OF THE FATHER IN EARLY LIFE}

Pantelie Speranța Rodica ${ }^{7}$

\begin{abstract}
The present paper is an attempt to create bridges of understanding between the subjective investigation in the psychoanalytic situation and the empirical research concerning a subject not enough explored in its earliest dimensions - the place and role of the father in the first year of the child's life. As part of a more extensive empirical research on the dynamics of child development in the first year of life, the research presented in this article was built and articulated within the psychodynamic theories of development, it was conducted in the form of a standardized research and generated a series of results that are re-integrated into the psychoanalytic understanding, validating and being validated by psychoanalytic knowledge. The central point of this encounter between the psychodynamic understanding and the results of empirical research is that the father is an active presence in the development of the child from the first year of life, in a formula of internal and external triadic relationship and that one of the most important function of the father in this early stage of life is to facilitate a way for the child to build his own loving and creative relationship with the world.
\end{abstract}

Key words: father, dyad, triad, psychic space, separation, development.

\section{Introduction}

The present work is the result of a personal urge for understanding the deep, complex and intense processes in which the human mind arises at the beginning of life. The work starts from a phrase heard many years ago in a psychoanalytic conference and has become both a

\footnotetext{
${ }^{7}$ West University of Timisoara; pansper2000@yahoo.com
} 
basis for understanding and an internal interrogation ever since: the mind is born in love relationships.

The theme of the article follows the path of that interrogation and of those beliefs derived from it, being part of a more extensive empirical research, which, at first, followed the psychodynamic knowledge and weaved around the idea of investigating, substantiated through an objective methodology, based on standardized methods and on my personal understanding of psychoanalytic theories, the specifics of the primitive mother-infant dyad as the matrix of the beginnings of human mind. The research results introduced us also to a slightly different road, however, even more interesting, which came to confirm more recent research and interests in the field of psychoanalysis and providing for the author a better understanding of what is happening in the psychoanalytic setting. The answer to the question: "Who is the child weaving with the essential love relationships in which his mind will rise at the beginnings of life?" headed, following the research, from an exclusive mother-child dyad to the mother-father-child triad and from an exclusive attention given to the primitive mother, to the consideration of the existence of a primitive paternal psychic presence and function. In the same time, based on these empirical results, this article is also an invitation to reflection and discussion on the role and the function of the father in the first year of life.

Emde \& Fonagy noted that, although from its very beginning psychoanalysis provided ,an extraordinarily innovative body of knowledge” (Emde \& Fonagy, 1997, p.643) putting in its service the investigative curiosity of the analysts, somewhere along the road it got away from universities and research and accepted as the sole source of knowledge and understanding the psychoanalytic situation, partially ignoring progress in empirical research. In this context, the authors plead for the opening of psychoanalysis to diversify the methods of knowing and validating psychoanalytic knowledge. It also pleads for the opening of psychoanalysts to the joy and creative tension that the expectation and surprise of confirming or rejecting of a theory and the vitality that this confrontation can generate in the psychoanalyst's work.

The present paper aims to answer, in part, even if from a slightly different perspective to that introduced by the authors quoted, this need for research and validation of the psychoanalytic postulates in a multi-method way and to try building a connecting bridge between subjectivity of the conclusions derived from psychoanalytic work with patients and the need for a more objective and standardized validation for theoretical positions on the dynamics of mental functioning in the first year of life.

Therefore, starting from a psychodynamic conceptualization of the primitive psychic processes and dynamics during the first year of life, the work presents several results of a 
research based on a standardized and objective methodology, then using these objective validations as the starting point for some thoughts regarding the psychodynamic meanings derived from these results.

\section{Was there a dyad or a triad at the beginning?}

The reality of contemporary societies faces a variety of individual or family situations, hard to imagine even a few years ago and for which psychology and sometimes psychoanalysis do not have an immediate or fully adaptive response: families with children living with the mother and father in a normal family context, children living in divorced couples, maybe with a stepfather, children living with single mothers, children living with fathers alone, children who know their fathers and have a relationship with them, even if they do not live with them, children who do not know their fathers and have no relationship with them, sometimes not even knowing the identity of their father, always leading to difficulties in registering in a transgenerational identification lineage, children raised by grandparents, children who grow up in state institutions; there are so many other possible realities. What remains constant in all these constructions of reality is that in subjective reality there are never children without fathers. Even children whose fathers are not constantly present in their lives, physically or symbolically, have in them, inevitably, the image and meaning of a father and, to a large extent, the mother is the one who makes accessible for the child this vital constant inner presence in order to facilitate the emerging of an internal meaning and the construction of personal identity.

If motherhood is one of the favourite subjects of research in psychological and psychoanalytic literature, when discussing the ontogenesis of human mind, fatherhood has gained its place harder and only more recent in a systematic labour of understanding and investigation, although the issue of the father's role in child development was one of the first concerns of Freudian psychoanalysis. For that matter, Lamb et al. (1985), who notes, among others, the absence of the father in all areas of social sciences, not only from psychoanalysis, questioned this implicit inference of maternal exclusivity on the infant. The absence of studies on fatherhood is especially acute if we refer to the role of the father in the first year of life. What is evident is that studies about the father focused especially on the place and its important role starting from the Oedipal period through the latency towards adolescence, exhibiting a sort of concern as to not usurp the place devoted to the mother and thus neglect the father's role in the first moments of life. When talking about this problem, the trend is rather to punctuate, in a 
known scenario of the specificity of maternal care in the first year of life, those small areas where the father could introduce differences in the care process (Chiland, 1982).

Chronologically, Freud introduced only the "pre-oedipal mother" as a defining figure for this first period of development: a mother who nourishes and seduces the child in a complex care process, often without considering giving the father a role during this period. As Chiland (1982) underlies, he introduced a paternal function in relation to the primary identification, without assuming however the explicit role of the father when he says that this identification is made with both parents, differentiating between them not being accessible to the child as long as he has no access to understanding the difference between the sexes.

For a long time, until the early 1940s, psychoanalysts deemed the primary identification as one realized exclusively with the mother, introducing the father only in connection with oedipal triangulation, and thus consecrated the concept of exclusive dyad in the child's relational dynamics during the first year of life. The triad and the father's image in relation to the child remained for many years one mainly anchored in the oedipal function of the father (Chiland, 1982).

As Jones (2007) noticed, only since the second half of the 1970s and the early 1980s, authors began to bend with more interest towards the pre-Oedipal father, whom Ross (1979) called "the forgotten father" of psychoanalytic literature. More recently, the father became more an object of interest to psychoanalysts. Taking into consideration this increased focus on the importance of the father in the first moments of life, Von Klitzing, Simoni, and Bürgin (1999) get to talk about the triad as defining as well the primary relationship and the relational context in which the child is born, the dyad being, in their opinion, not so much of an experience lived earlier and more at the origin, but more likely an illusion of a symbiotic duality.

The theories that state the exclusive dyadic character of the first life period were challenged also by various results obtained in systematic developmental research, which showed, for example, that, since the beginning of life, infants have the life skills to recognize, on the basis of behavioural markers, and to relate to more than one person of care (Papousek \& Papousek, 1987).

\section{The function and role of the father in the first year of life}

In identifying these dimensions of paternity, we can start from Lamb's claim (1976), which suggests that what matters in the first place is the quality of the relationship with a father, fundamentally more important than the physical presence of the father. The function/role of the 
father does not exist in itself. Its construction implies a complex exercise of creation and lifelong learning, a long process of becoming at the end of which we find a father in relation to a child, each time being father in a different way with each of his children.

The presence of the father and his role in the early period of life are essential, partly because it is a kind of preparation of the internal relations and developments that will occur starting with the second year of the child's life and essentially because they are preparing the child for the meeting with the wider external world and for active participation in the world (Ross, 1983).

Herve et al. (2000) take into account the existence of the early triadic interactions and speak of a phenomenon that they call "imaginary triangulation", a very early developmental process, involving the construction by each subject of "schemes of three together". In other words, parents who have a mental representation of the mother-father-infant relationship as a three-together will generate in their interactions a psychic space in which the baby relates to each of them, as a primary condition for him to devise and to develop subsequently a threetogether scheme.

Dolto (1988) also shows that what appears to be an indissolubly and vital dyad mother-infant after the birth of the newborn, is, in fact, from the beginning, a triangulation, because the mother contains the father in her mind when interacting with the newborn and introduces him to the newborn. The same goes for the father, who contains the mother in his mind and presents her to the infant.

Current research on early mother-father-infant interactions demonstrates the development at the same time of the triadic relationships between the infant and its two parents in the developmental context, these triadic relationships pursuing in parallel to dyadic interactions. Dyadic and triadic interactions allow for the affective attunement and the triadic alliance: the mother and the father share with the baby not only gestures and actions (of care and stimulation), but even their psychic reality. Three-together means more than two-plus-one.

\section{Methodology of the research - population, instruments, results}

The study whose results are presented, providing a basis for understanding the realities it covers in a psychodynamic key, namely the place and role of the paternal function in the first year of life, was a correlational one attempting, through correlations and multiple linear regression, to identify maternal and paternal influences on the development of communication skills and socio-emotional abilities in the first year of life. This article examines the paternal 
influences on a child's development in the first year of life, but also the way the father manages to identify with his paternal function and to make an effective exercise of it in his relationship with the child during the first year of life.

The research was carried out on family dyads and triads, involved in research being 101 children aged 1 month to 13 months; 100 mothers of these children and 75 fathers, respectively 74 mother-father-newborn triads; 1 father-newborn dyad and 26 mother-newborn dyads. The reason for the uneven number of mothers and fathers was the lack of availability of fathers to participate in the research, although they lived with the mother and the baby from the very beginning.

In total, 276 subjects were evaluated, the questionnaires used to measure the variables defining the development of the newborn being supplemented by the primary care person - in most situations, the mother.

The research used standardized measuring instruments, which aimed to highlight the specific elements of the exercise of the paternal role during the first year of life and their effects on the communication skills, socio-emotional characteristics and the resilience strategies of the child, namely its ability to establish meaningful relationships and to engage actively, to have initiative in creating the conditions for satisfying its own needs in the first year of life.

In a brief presentation of the instruments used, we can mention a number of instruments utilized to measure the paternal and maternal variables: for the maternal/paternal self-esteemassessment - The Rosenberg Self Esteem Scale (Rosenberg, 1965); for the specifics of the romantic attachment relationships of the parents - ECR-R. Experiences of Close Relationships - revised (original version - Brennan, Clark \& Shaver, 1998; revised - Fraley, Waller \& Brennan, 2000), adapted for the Romanian population (Negrei \& Sava, 2007); for the evaluation of primary attachment patterns of the parents - Parental Bonding tool (PBI) (Parker, Tupling \& Brown, 1979); for measuring the parental reflective capacity - The Parental Reflective Functioning Questionnaire (PRFQ) (Luyten, Mayes, Nijssens, \& Fonagy, 2017); for assessing the depressive feelings of parents - Edinburgh Postnatal Depression Scale EPDS (Cox, Holden, \& Sagovsky, 1987) and CES-D Questionnaire (Center for Epidemiologic Studies Depression Scale (CES-D) (Radloff, 1977); for the sense of competence and self-efficacy in the exercise of parental functions - The Maternal Efficacy Questionnaire (MEQ) (Teti \& Gelfand, 1991); for maternal separation anxiety - Maternal Separation Anxiety Scale-MSAS (Hock, McBride \& Gnezda, 1989); to measure the feeling of parenting perceived as overwhelming, lacking in satisfaction and stressful - Parenting stress index (Short Form); for the emotional maturity of 
parents - Friedman Emotional Maturity Questionnaire; for assessing the parental postnatal attachment - Maternal Postnatal Attachment Scale/Paternal Postnatal Attachment Scale (Condon \& Corkindale, 1998; Condon et al., 2008). For measuring child skills and competences in the first year of life: communication skills and competence - Communication and Symbolic Behavior Scales: Developmental Profile. Infant/Toddler Checklist (CSBS DP Infant-Toddler Checklist (Wetherby \& Prizant, 2002); relational competences and the resilient behaviour strategies of the child - Devereux Early Childhood Assessment for Infant/Toddlers-DECA I/T (Mackrain, LeBufee \& Powell, 2007).

The results regarding the father's influence on the child's development in the first year of life have highlighted significant correlations between the expressive and symbolic communication skills of the child and the paternal reflective capacity manifested in the form of interest and curiosity towards the child $(.332 *)$, the pattern of primary paternal attachment based on a caring relationship with his own mother $\left(.294^{*}\right)$; between the relational and emotional competences of the child and the paternal depression (-.231*), the postnatal paternal attachment organized around an attitude of patience and tolerance of the father relative to the newborn $\left(.298^{*}\right)$ and the paternal stress caused by the relationship with a child perceived as difficult $\left(.237^{*}\right)$ and by the difficulties perceived by the father in managing paternal tasks $(-.349 *)$; between the child's resilience expressed in terms of personal initiative and the father's feeling of competence and self-efficacy $(.362 *)$, the postnatal paternal attachment organized around an interaction felt as excited and joyful $\left(.229^{*}\right)$ with a child positively invested and regarded with affection and pride $\left(.240^{*}\right)$, the paternal reflective capacity of the father organized around the recognition of the child's own mental states $\left(.226^{*}\right)$ and the paternal stress generated by the perception of the child as difficult (-.299*); the same applies to resilient behaviours based on the establishment of positive attachment relationships of the child, which correlates with the father's feeling that he is an effective father $\left(.236^{*}\right)$, with a postnatal paternal attachment to a child cared for with affection and pride $\left(.228^{*}\right)$, the paternal stress generated by the perception of the child as difficult (-.362**) and of the interaction with the child as dysfunctional $(-.430 * *)$.

It is interesting and important to note that in almost all the studied relationships, the parents' resources and vulnerabilities appeared in a consistently complementary manner, advocating for the idea that, from the outset, the parental couple must work as an emotional and instrumental partnership around the child and that the presence of the child allows, in each of the parents, both the discovery of unknown resources and the possibility to work out, sustained by the other parent and even by the child, those areas of vulnerability or internal conflict that he had not had access to until that time. This could be the meaning of the literature allegations 
that the relationship of care around a child, especially in the first year of life, is an endeavour to construct new identities, both a challenge and an evolution.

The study also highlighted, as a result of an analysis that used multiple linear regression, the most important predictors of the sense of self-efficacy and paternal competence and its opposite, the living of the paternal function with feelings of uselessness, incompetence and depression.

Thus, with regard to the father's sense of competence and self-efficacy, the most important predictors identified were the self-esteem of the father and the self-esteem of the mother, as well as the father's capacity to see the people around him, the child included as having their own needs, wishes and fears, the feeling that he is valued and respected as a child's partner and father by the mother, all these dimensions exerting a positive influence on the sense of paternal competence. Another predictor of the father's sense of competence is the primiparity, which exerts, at least in a first stage of fatherhood, a negative and anxious influence.

As for the perception of fatherhood with feelings associated with depression and uselessness, its most important predictors were the paternal reflective functioning ignoring the individuality of the psychic reality of child, the feeling of being overwhelmed and the stress of the father in the exercise of the paternal function, the lack of support and involvement of the partner in the relationship with the father and a paternal pattern of primary attachment with an over protective mother.

\section{Discussion}

The results of the empirical research on fatherhood presented here, conducted within the more extensive study on the psychic and relational dynamics of the first year of life, come to confirm a series of insights and clinical discoveries of psychoanalysis in terms of building paternal identity, as well as the place and role of the father in the child's first year of life.

First of all, the results come to confirm the finding, increasingly evident among clinicians, analysts and researchers, of the difficulty and the complexity which the first time to become a father involves, leading to an identity reorganization and the mobilization and working through of the primitive mental contents, in order to allow to the father to enter the paternity with maximum emotional availability (Feldman, Nash, \& Aschenbrenner, 1983). The ability of the father to put his wish for children in the service of his paternal exercise in order to allow him to establish a good relationship with his children depends on the emotional quality of his early relationships (Zayas, 1987). In this respect, Jacobson shows that the destiny of the 
father-child relationship is facilitated by the quality of the identifications with his own father and by the manner in which he come to terms with the rivalry with his brothers (Jacobson, 1950, p.145). Also Jacobson states that it is a father's love, and not necessarily the threat of castration, which facilitates the resolution of the Oedipal conflict, so that a loving father who made himself available for the child from the beginning (and for the mother, we added), long time before he becomes a tyrannical rival, has a strong contribution to a positive paternal identity of the child becoming an adult and a father. As the results of the study shown here showcase, by linking the sense of paternal competence and also the feelings of powerless and depression towards the paternal role with the father's primary attachment patterns, self-esteem and its reflective capacity, we can understand that the paternal identity, the way of living it and its exercise at the start of life, depend on the successful identifications with the caring and creative functions of the father's mother and father. This is also relevant if we analyse the link between the father's feeling of being overwhelmed and of depression and the reflective functioning of a prementalising type and a paternal primary attachment pattern with an overprotective mother. A father who grows up in a caring relationship with a mother who has difficulty in giving up the dyadic fusion and allowing the child's father to exercise the function of separating and attracting the child to the world, with a mother who sees her child as an extension of herself, both of them being caught in a merged relationship where no space is being made for the third, will give rise to a paternal identity - of the one who was once the child of this mother - unable to exercise his role and functions in the relationship with his own child. A father who bears the mark of a history of this kind will have difficulty in narcissistically investing his own child, in marking him as a worthy partner who deserves the father's time and attention, that is, a place in his own psychic space. In the absence of this investment of the father in the child, the role of the third or the other that facilitates separation and stimulates the pleasure of the active positioning in relation to the world will fail, with consequences for the child's ability to communicate himself to the others and on his creativity and adaptation to the outer world.

The assumption and exercise of the paternal role, as shown by the study data presented, also depend significantly on the organization and dynamics of the couple, the paternal function being inextricably articulated with the maternal function. Brazelton and Cramer (1991) believes that a number of factors are involved in creating the father: a predisposition to parenting, generated by a positive child history with their own parents; the interactive availability of the newborn and his ability to make himself seen and felt in all its vitality, thus activating the availability of the paternal function; the sociocultural legitimacy of paternity, with the roles and social representations the community associated with it, but also the legitimacy of the father 
status in his own family; and especially, the way his partner authorizes him in his paternal function and makes him feel validated, as long as the mother is the one who introduces the newborn to the father and the father to the newborn, making his partner the father of that child. This idea is not new, it also appears in Winnicott (1964): "it depends on what mother does about it whether the father does or does not get to know the baby". (Winnicott, 1964, p. 81). The quality of the affective relationship between the mother and the father is a vital moderator of the father-child relationship.

The question may arise: why is this so important and why is it important that the mother, in her turn, to be able to see her baby and the father of the child as partners with equal rights in this development phase? Firstly, because, as Winnicott (1964, p.115) says, for the baby it is much easier to have two available parents, in such a relational configuration that allows him to always preserve a loving parent available, in spite of the hateful attacks on the other, with consequences in his psychic stability.

Secondly, because, as Marks (2002) says, it offers to the child a sense of a sexual creative couple kept in his mind without conflict or avoidance, with consequences in his longtime creative capacity: "I suggest that the presence of a sexual father and mother couple, in each of the couple's minds, determines both the extent to which a woman will welcome her sexual partner into the relationship she has with their infant, and whether or not he will be able to become involved. This configuration, in each of the partners' minds will affect whether or not their child can have in its mind a linked mother and father. It also lays the ground for the development in the child of a certain creative kind of mind and the capacity as an adult and parent to welcome a sexual and potent father" (Marks, 2002, p. 93).

We thus come to the functions and role of the father at the beginning of the child's life. As Winnicott (1964) shows, one of the first, most important and difficult functions of the father is to survive the child's hatred directed by the child towards him when the child perceives him as disappointing or frustrating. The father must contain and integrate into his mind, modifying them for the baby, intense primitive affects, psychotic fears, and projective identifications. In other words, the father, alongside the baby's mother - and sometimes protecting the mother from the hatred of the baby by making himself available to the baby as the indestructible object of his hatred - has to be sensitive and to contain the child.

In direct connection with this function, it is also the essential paternal dimension of the "third", the "Other", which separates, differentiates and allows the child the self-experience in a wider psychic space. From this perspective, the father was recognized in the psychoanalytic literature as being an important factor of mediation facilitating the transition "from the womb 
to the world" (Seligman, 1982, p. 10), in disentangling the child from regressive symbiotic relations with the mother (Abelin, 1975), in using its symbolic function of the third person to break the collusion between the mother and the child, thus becoming meaningful to life (Lacan, 1979) and facilitating the child's access to symbols and language. Abelin brings also into question the role of the father in offering a "distant", "non-maternal" space for the child's enthusiastic exploration of reality (Abelin, 1971, p. 246).

In direct connection with the two functions already analysed, another dimension of the paternal function emerges, which is essential in the primitive period of mental development, that being the role of introducing reality to the baby and the enlargement and integration of the internal and external reality into a large three-dimensional psychic space (my underlining) (Brickman, 1993). The father is a representative of reality, external and psychic alike, in so far as objective reality cannot exist outside a subjective experience of this reality. The representation of the reality that the father gives to the child offers the opportunity to refer and confront, in order to integrate the differences, says Brickman, offering the alternative to the undifferentiated internal/external world of symbiosis with the mother (where psychic and external realities often merge) - an inner sense of the outer world. In this way, the triadic experience becomes an essential factor in the orientation of the child's self-experience in a widened psychic space, allowing the child to practice "the experience of being-in-the-world" (Brickman, 1993, p. 907). Through this function of active agent of the tri-dimensional world, the father introduces the world to the child as a challenging experience and, as Mahler says, borrowing Greenacre's term (1957), he thus writes the beginning of the "child's love affair with the world" (Mahler et al., 1975, p.71). Aggressiveness-like-game, an essential element of paternal behaviour and of the father's relationship with the child allows the child to creatively combine love and aggression in the service of adaptation and make the father a facilitator of a balanced relationships between the maternal object and the outer world (Brickman, 1993).

Turning to the results of the empirical research that started these interrogations and this invitation to reflection on these topics, it becomes easier to understand the meaning of the positive correlations between the child's ability to communicate and to communicate himself to the world and to position himself actively in relation to the world in order to activate the resources of satisfying his needs and those factors sustaining the paternal function, such as a father's love story with a mother whose investment in the child is positive and healthy, allowing him an early access to the benefits of the triad and permitting him to structure itself as a person able to mentalize and differentiate. 
It also becomes easier to understand why the child will become emotionally competent and able to establish meaningful and satisfying relationships if he has at his disposal a father who is capable of joyfully exercising his paternal functions, in a relationship of three-together with a child narcissistically and objectually invested as worthy of love and interest and with a mother who allows the relationship of love between father and child and can use the function of emotional attunement of the father to make her own differentiations in relation with her baby.

With certainty, the study presented here succinctly, as an attempt to illustrate the continuity between psychodynamic theories and empirical research has a number of limits, making it necessary to continue the investigation through observational methods and qualitative methods rather specific to the psychodynamic approaches. Firstly, the study was conducted exclusively on the Romanian population and addressing the Romanian cultural space. Secondly, the relative reduced number and homogenous character of the studied population, consisting of mothers and fathers with high levels of education and an increased motivation for parenting, reduce the statistical power of the results and limit the transference of the results to the larger population. These two limitations are also the reason for not using the conclusions of this study as being generally valid, requiring further investigation. Also, the investigation is required to continue by using qualitative methods, which give more access to the inner experience of parents around parenthood.

It is, however, a beginning point in a Romanian cultural and scientific space from which such approaches to understanding the role and place of the father in the primitive period are nearly non-existent, an invitation to reflect on the role and the function of the father as an important factor in the genesis of the human mind from the beginnings, as well as an attempt to weave bridges of understanding and mutual validation between psychodynamic theories, clinical intuitions in the analytical room and the objective research, which can bring additional openness or new perspectives of integration of psychodynamic theories with the realities of our times.

\section{Conclusion}

The central idea of this article - seen as a meeting point between the psychodynamic deep understanding of the development and functioning of the human mind and the potential for further understanding or validation that empirical research can provide - is that the father is a significant subjective presence from the very beginnings in the psychic space, relationships and emotional life of the child, as the child is also present before it even physically exists in the 
minds, desires and fantasies of his parents, and that the relationship that is weaved in this formula of internal and external meeting, triadic from the beginning, highlights an essential function of the father, his huge responsibility to facilitate a way for the child to build his own love story with the world throughout his whole life.

\section{REFERENCES}

ABELIN, E.L. (1971). The Role of the Father in the separation-individuation process. J.B. McDevitt \& C.F. Settlage (Eds.), Separation-Individuation. International Universities Press, New York, pp. 229-252.

ABELIN, E.L. (1975). Some Further Observations and Comments on the Earliest Role of the Father. Int. J. Psycho-Anal. 56: 293-302.

BRAZELTON, T.B., Cramer, B.G. (1991). The Earliest Relationships. Karnac Books, London, pp. 272.

BRICKMAN, H.R. (1993). 'Between the Devil and the Deep Blue Sea': The Dyad and the Triad in Psychoanalytic Thought. Int. J. Psycho-Anal. 74:905-915.

CHILAND, C. (1982). A New Look at Fathers. Psychoanal St Child 37:367-379.

DOLTO, F. (1988). Tout est langage [Everything is Language]. Ergo Press, Paris, pp. 132.

EMDE, R.N. and Fonagy, P. (1997). An Emerging Culture For Psychoanalytic Research? Int. J. Psycho-Anal. 78:643-651.

FELDMAN, S. S., Nash, S. C., \& Aschenbrenner, B. G. (1983). Antecedents of fathering. Child Dev 54(6)1628-1636.

HERVE, J., Lamour, M., Moro, M.R., FIvaz-Depeursinge, E., Maury, M. (2000). Analyse des interactions triadique precoces. Co-construction des outils conceptuels et methodologique. Maury, M., Lamour, M. (2000). Alliances autour du bebe: recherché a la Clinique. PUF, Paris, pp. 27-63.

JACOBSON, E. (1950). Development of the Wish for a Child in Boys. Psychoanal. St. Child, 5:139-152.

JONES, K. A. (2007) Assessing the Impact of Father-Absence from a Psychoanalytic 
Perspective, Psychoanal Soc Work 14:1, 43-58.

LAMB, M.E. (1976). The Role of the Father: An Overview. In M. E. Lamb (Ed.), The Role of the Father in Child Development. New York: Wiley, pp. 1-63.

LAMB M.E., Pleck J.H., Levine J.A. (1985). The Role of the Father in Child Development. In: Lahey B.B., Kazdin A.E. (eds) Adv Clin Child Psycho. Springer, Boston, 8: 229-266.

MAHLER, M.S., Pine, F. \& Bergman, A. (1975). The psychological birth of the human infant: Symbiosis and individuation. New York: Basic Books.

MARKS, M. (2002). Letting fathers in. In J. Trowell \& A. Etchegoyen (Eds.), The importance offathers. New York: Brunner-Routledge. pp. 93-106

PAPOUSEK, H., \& Papoušek, M. (1987). Intuitive parenting: A dialectic counterpart to the infant's integrative competence. In J. D. Osofsky (Ed.), Wiley series on personality processes. Handbook of infant development. John Wiley \& Sons, Oxford, pp. 669-720.

ROSS, J.M. (1983). Father to the Child: Psychoanalytic Reflections. Psychoanal. Rev. 70(3):301-320.

ROSS, J.M. (1979). Fathering: A Review of Some Psychoanalytic Contributions on Paternity. Int. J. Psycho-Anal. 60:317-327.

SELIGMAN, E. (1982). The Half-Alive Ones. J. Anal. Psychol. 27(1):1-20

VON KLITZING, K., Simoni, H. and Bürgin, D. (1999). Child Development and Early Triadic Relationships. Int. J. Psycho-Anal. 80(1):71-89

WINNICOTT, D. W. (Ed.). (1964). The child, the family and the outside world. Penguin Books, London, p. 81

ZAYAS, L.H. (1987). As Son Becomes Father. Psychoanal. Rev. 74(4):443-464 